JURNAL OF MIDWIFERY CARE:

VOL. 01 NO. 02, JUNI 2021

DOI: $10.34305 / \mathrm{jmc} . \mathrm{V} 1 \mathrm{i} 02.307$
Ciptaan disebarluaskan di bawah

Lisensi Creative Commons Atribusi-

NonKomersial-BerbagiSerupa 4.0

Internasional.

\title{
HUBUNGAN PENGETAHUAN DENGAN PERILAKU IBU NIFAS DALAM PERAWATAN LUKA PERINEUM DI WILAYAH KERJA UPTD PUSKESMAS SUKAMULYA DAN KADUGEDE
}

\author{
${ }^{1}$ Nurul Hikmah, ${ }^{2}$ Fera Riswidautami Herwandar, ${ }^{3}$ Mala Tri Marliana, ${ }^{4}$ Siti Hodijah
}

Sekolah Tinggi Ilmu Kesehatan Kuningan

nurulhikmah128@gmail.com

\begin{abstract}
Abstrak
Persalinan seringkali mengakibatkan robekan jalan lahir. Dimana faktor yang mempengaruhi perawatan luka perineum yaitu pengetahuan dan perilaku. Tujuan penelitian untuk mengetahui hubungan pengetahuan dengan perilaku ibu nifas dalam perawatan luka perineum di Wilayah Kerja UPTD Puskesmas Sukamulya dan Kadugede. Jenis penelitian analitik dengan rancangan korelasional. Responden berjumlah 30 orang menggunakan teknik accidental sampling. Analisis data menggunakan korelasi Spearman Rank dengan instrumen berupa kuesioner. Hasil analisis univariat hampir setengahnya ibu nifas memiliki pengetahuan baik sebanyak 43,3\%, dan sebagian besar memiliki perilaku yang optimal sebanyak $70 \%$. Analisis bivariat ada hubungan yang signifikan antara pengetahuan dengan perilaku ibu nifas dalam perawatan luka perineum dengan nilai $\rho=0,001$ dan nilai $r=0,774$ artinya memiliki kekuatan yang kuat. Ibu nifas di Wilayah Kerja UPTD Puskesmas Sukamulya dan Kadugede diharapkan dapat bertanya kepada ibu yang sudah berpengalaman dalam perawatan luka perineum, mencari tahu lewat media sosial ataupun bisa bertanya langsung kepada petugas kesehatan/bidan agar dapat memperluas pengetahuan ibu tentang perawatan luka perineum.
\end{abstract}

Kata Kunci $\quad$ : Pengetahuan, Perilaku, Perawatan, Luka Perineum

\section{Pendahuluan}

Periode pasca persalinan merupakan masa transisi kritis bagi ibu, bayi, dan keluarganya secara fisiologis, emosional dan sosial baik di negara maju maupun negara berkembang seperti di Indonesia, perhatian utama bagi ibu dan bayi terlalu banyak tertuju pada masa kehamilan dan persalinan, akan tetapi resiko kesakitan dan kematian ibu serta bayi lebih sering terjadi pada masa pasca persalinan. Hal ini berarti kemampuan untuk memberikan pelayanan kesehatan masih memerlukan pelayanan yang lebih bermutu (Chasanah et al., 2015). 
JURNAL OF MIDWIFERY CARE:

VOL. 01 NO. 02, JUNI 2021

DOI: $10.34305 / \mathrm{jmc} . \mathrm{V} 1 \mathrm{i} 02.307$
Ciptaan disebarluaskan di bawah

Lisensi Creative Commons Atribusi-

NonKomersial-BerbagiSerupa 4.0

Internasional.
Dikatakan bahwa Persalinan seringkali mengakibatkan robekan jalan lahir, baik pada ibu primigravida maupun ibu multigravida. Menurut Liu dalam Khusniyati et al. (2016) diperkirakan 85\% ibu bersalin mengalami robekan di jalan lahir. Data statistik baru-baru ini menunjukkan bahwa sekitar $75 \%$ wanita yang melahirkan pervaginam akan mendapat jahitan di perineum.

$$
\text { Robekan perineum biasanya }
$$
robekan yang terjadi pada garis tengah dan dapat juga meluas jika kepala dari janin dilahirkan terlalu cepat. Perineum adalah daerah yang tidak mudah untuk dijaga. Jika perawatan luka pada perineum tidak baik, maka dapat terjadi infeksi yaitu peradangan pada semua alat genetalia ibu yang ditandai dengan meningkatnya suhu badan ibu singga ke suhu $38^{\circ} \mathrm{C}$, sehingga dapat juga mengakibatkan komplikasi infeksi kandung kemih sampai infeksi pada jalan lahir ibu, bahkan menimbulkan kematian ibu (Varney, 2008).

Berdasarkan hasil Survei Penduduk Antar Sensus (SUPAS) di Indonesia bahwa Angka Kematian Ibu (AKI) tahun 2015 mengalami penurunan sebanyak 305/100.000 kelahiran hidup. Penyebab angka kematian ibu diantaranya disebabkan infeksi masa nifas yang menyumbang sebesar 7,3 \% (Kemenkes RI, 2016) dan berdasarkan hasil survey yang dilakukan Dinas Kesehatan Provinsi Jawa Barat (2012) melaporkan sebanyak 818 orang (87,99/100.000 kelahiran hidup). Penyebab kematian secara langsung pada persalinan dengan komplikasi diantaranya adalah perdarahan, infeksi jalan lahir serta emboli, dan robekan jalan lahir.

Menurut Herawati (2010) bahwa faktor-faktor yang mempengaruhi penyembuhan luka perineum pada ibu setelah melahirkan beberapa diantaranya seperti pengetahuan, cara perawatan, dan personal hygiene. Ibu nifas yang terdapat luka perineum diharapkan mempunyai pengetahuan dan perilaku yang baik sehingga dirinya dapat melakukan perawatan luka perineum dengan baik.

Menurut (Notoatmodjo, 2010) hasil penginderaan manusia, atau hasil tahu seseorang terhadap objek melalui indera yang dimilikinya (mata, hidung, telinga, dan sebagainya) disebut pengetahuan (knowledge) sedangkan yang dimaksud dengan perilaku yaitu semua kegiatan atau aktivitas manusia baik yang dapat diamati langsung maupun yang tidak dapat diamati oleh pihak luar.

Perawatan luka perineum menurut (Bahiyatun, 2009) bisa dilakukan dengan 
JURNAL OF MIDWIFERY CARE:

VOL. 01 NO. 02, JUNI 2021

DOI: $10.34305 / \mathrm{jmc} . \mathrm{V} 1 \mathrm{i} 02.307$
Ciptaan disebarluaskan di bawah

Lisensi Creative Commons Atribusi-

NonKomersial-BerbagiSerupa 4.0

Internasional. mencuci genetalia dengan sabun dan air bersih setelah berkemih dan defekasi, serta mencuci tangan sampai bersih. Infeksi dapat terjadi, tapi sangat sedikit kemungkinannya jika perineum dirawat dengan baik. Menurut (Rukiah, 2010) parameter yang dapat digunakan dalam evaluasi hasil perawatan adalah perineum tidak lembab, posisi pembalut tepat, dan ibu merasa nyaman.

Berdasarkan hasil penelitian (Raudhatul J., 2013), dalam penelitiannya mengenai hubungan pengetahuan ibu nifas dengan perawatan luka ruptur perineum didapatkan ada hubungan antara pengetahuan ibu nifas dengan perawatan luka ruptur perineum dengan nilai $\rho=0,045$. Pengetahuan yang baik dalam melakukan perawatan luka perineum tersebut akan sangat membantu dalam proses penyembuhan luka perineum.

Berdasarkan studi pendahuluan yang dilakukan dengan wawancara di Wilayah Kerja UPTD Puskesmas Sukamulya dan Kadugede pada tanggal 13 Februari 2019 terhadap 10 orang responden ibu nifas sebagian besar $40 \%$ tidak tahu tentang perawatan luka perineum dan sebesar $30 \%$ perilaku ibu nifas untuk melakukan perawatan luka perineum masih salah dan peran paraji yang ada di wilayah tersebut sudah tidak aktif lagi dalam perawatan luka. Dari uraian latar belakang tersebut, maka peneliti tertarik untuk melakukan penelitian mengenai "Hubungan Pengetahuan dengan Perilaku Ibu Nifas dalam Perawatan Luka Perineum di Wilayah Kerja UPTD Puskesmas Sukamulya dan Kadugede”.

\section{Metode}

Jenis penelitian ini adalah kuantitatif dengan metode penelitian survey analitik dengan rancangan korelasional. Populasi dalam penelitian ini adalah ibu nifas yang terdapat luka laserasi di Wilayah Kerja UPTD Puskesmas Sukamulya dan Kadugede pada bulan juni sebanyak 58 responden. Sampel yang diambil dalam penelitian ini adalah ibu nifas yang memiliki luka laserasi perineum di Wilayah Kerja UPTD Puskesmas Sukamulya dan Kadugede yang memenuhi kriteria inklusi dan eksklusi. Variabel bebas dalam penelitian ini adalah pengetahuan ibu nifas. Variabel terikatnya adalah perilaku ibu nifas. Analisis yang digunakan adalah analisis univariat dan analisis bivariat. 


\section{Hasil}

\section{Analisis Univariat}

Tabel 1. Distribusi Frekuensi Pengetahuan Ibu Nifas tentang Perawatan Luka Perineum

\begin{tabular}{ccc}
\hline Variabel & Frekuensi (f) & Persentase (\%) \\
\hline Pengetahuan & & \\
Baik & 13 & 43,3 \\
Cukup & 11 & 36,7 \\
Kurang & 6 & 20 \\
Total & 30 & 100 \\
\hline Perilaku & & \\
Optimal & 21 & 70 \\
Tidak Optimal & 9 & 30 \\
Total & 30 & 100 \\
\hline
\end{tabular}

Sumber : Hasil Penelitian

Berdasarkan tabel 1, dapat diketahui bahwa dari 30 responden, hampir setengahnya ibu nifas memiliki pengetahuan baik tentang perawatan luka perineum sebanyak 13 responden $(43,3 \%)$.
Selain itu dapat diketahui pula bahwa dari 30 responden, sebagian besar ibu nifas memiliki perilaku yang optimal dalam perawatan luka perineum sebanyak 21 responden $(70 \%)$.

\section{Analisis Bivariat}

Tabel 2. Hubungan Pengetahuan dengan Perilaku Ibu Nifas dalam Perawatan Luka Perineum

\begin{tabular}{|c|c|c|c|c|c|c|c|c|}
\hline \multirow{3}{*}{ Pengetahuan } & \multicolumn{4}{|c|}{ Perilaku } & \multirow{2}{*}{\multicolumn{2}{|c|}{ Total }} & \multirow{3}{*}{ Nilai $P$} & \multirow{3}{*}{ Correlation } \\
\hline & \multicolumn{2}{|c|}{ Optimal } & \multicolumn{2}{|c|}{ Tidak Optimal } & & & & \\
\hline & $\mathbf{F}$ & $\%$ & $\mathbf{F}$ & $\%$ & $\mathbf{F}$ & $\%$ & & \\
\hline Baik & 13 & 100 & 0 & 0 & 13 & 100 & & \\
\hline Cukup & 8 & 72,7 & 3 & 27,3 & 11 & 100 & 0,001 & 0,774 \\
\hline Kurang & 0 & 0 & 6 & 100 & 6 & 100 & & \\
\hline
\end{tabular}

Sumber : Hasil Penelitian

Berdasarkan tabel 2, menunjukkan bahwa kelompok responden yang memiliki pengetahuan baik seluruhnya memiliki perilaku optimal sebanyak $100 \%$. Hasil uji statistik dengan menggunakan Spearman's rank diketahui didapatkan nilai $\rho=0,001$ dimana $<0,05$ dengan demikian ada hubungan antara tingkat pengetahuan dengan perilaku ibu nifas dalam perawatan luka perineum dan nilai $\mathrm{r}=0,774$ artinya memiliki kekuatan yang kuat. 
JURNAL OF MIDWIFERY CARE:

VOL. 01 NO. 02, JUNI 2021

DOI: $10.34305 / \mathrm{jmc} . \mathrm{V} 1 \mathrm{i} 02.307$
Ciptaan disebarluaskan di bawah

Lisensi Creative Commons Atribusi-

NonKomersial-BerbagiSerupa 4.0

Internasional.

\section{Pembahasan}

Analisis univariat

Berdasarkan tabel 1 menunjukkan bahwa dari 30 responden hampir setengahnya pengetahuan baik sebanyak 13 responden $(43,3 \%)$. Hal ini karena ibu nifas yang memiliki pengetahuan baik disebabkan oleh ibu sudah mempunyai anak (paritas multipara) dimana pada persalinan sebelumnya ibu mengalami luka pada perineum yang akhirnya perlu mendapatkan perawatan. Ibu sudah mendapatkan informasi atau penyuluhan dari tenaga kesehatan sehingga ibu sudah dapat memahaminya. Apalagi cara mendapatkan pengetahuan bisa didapat melalui pengalaman sendiri dan cara coba dan salah.

Hal ini sesuai dengan pendapat (Notoatmodjo, 2010), bahwa cara untuk memperoleh suatu pengetahuan dapat dilakukan dengan cara coba, salah dan pengalaman sendiri. Adapun pada ibu dengan paritas primipara didapatkan pengetahuannya baik disebabkan oleh ibu mempunyai pendidikan tinggi dimana pada ibu dengan pendidikan tinggi maka ibu mudah menerima informasi.

Hal ini sejalan dengan hasil penelitian (I'anah, 2013) tentang hubungan antara pengetahuan ibu nifas tentang personal hygiene pada luka perineum dengan penyembuhan luka fase proliferasi. Hasil penelitian sebagian besar pengetahuan ibu dalam kategori pengetahuan baik sebanyak 18 responden $(45,0 \%)$, hal ini dimungkinkan karena berbagai faktor-faktor yang dapat mempengaruhi pengetahuan seseorang salah satunya adalah informasi dimana informasi memberikan pengaruh kepada seseorang serta dapat juga dari pengalaman sebelumnya yang telah didapatkan.

Sebagian besar ibu banyak menjawab salah dalam pertanyaan pada soal nomor 13 mengenai cara yang baik untuk membersihkan kemaluan. Banyak ibu nifas yang menjawab bahwa cara yang baik untuk membersihkan kemaluan adalah dari arah belakang ke depan, padahal cara yang baik adalah dari arah depan ke belakang. Banyak ibu yang menjawab bahwa pada saat membersihkan perineum tidak memperhatikan proses pencuciannya apakah dari depan dulu ataukah dari belakang dulu. Menurut (Saleha, 2009) proses pencucian alat genetalia harus dimulai dari depan ke belakang agar tidak terjadi kontaminasi (masuknya) kuman dari anus ke perineum.

Berdasarkan tabel 1 diketahui bahwa dari 30 responden sebagian besar memiliki perilaku optimal dalam perawatan luka perineum sebanyak 21 responden $(70 \%)$. 
JURNAL OF MIDWIFERY CARE:

VOL. 01 NO. 02, JUNI 2021

DOI: $10.34305 / \mathrm{jmc} . \mathrm{V} 1 \mathrm{i} 02.307$
Ciptaan disebarluaskan di bawah

Lisensi Creative Commons Atribusi-

NonKomersial-BerbagiSerupa 4.0

Internasional.
Hal ini disebabkan oleh pengetahuan ibu yang baik sehingga ibu dapat mengerti dan mengetahui bagaimana melakukan perawatan luka yang baik agar tidak terjadi infeksi.

Pada ibu nifas memiliki perilaku optimal disebabkan oleh sebagian besar pengetahuannya baik, ibu mempunyai pendidikan menengah dan tinggi, sikap ibu yang positif, berusia 20-35 tahun sehingga ibu sudah siap dengan keadaannya. Pada saat ibu mengalami luka pada perineum ibu mencari informasi bagaimana perawatan luka yang baik. Apalagi untuk mengetahui perawatan luka perineum tersebut bukan saja didapat melalui pendidikan informal akan tetapi bisa juga didapat melalui media sosial ataupun cetak. Ditunjang lagi ibu dalam kondisi bekerja yang mengakibatkan kondisi ekonomi dalam keadaan stabil bahkan meningkat. Kondisi ekonomi ibu yang baik, maka segala keperluan bisa ibu dapatkan seperti melakukan kunjungan ke tenaga kesehatan, membeli obat, makan dengan menu gizi seimbang dan sebagainya yang dapat menunjang kesehatan ibu. Disamping itu juga dengan adanya dukungan dari suami dan keluarga dan adanya penyuluhan dari tenaga kesehatan dapat meningkatkan perilaku ibu menjadi lebih optimal.
Hal ini sesuai dengan pendapat (Notoatmodjo, 2010) bahwa perilaku itu sendiri ditentukan atau terbentuk dari 3 faktor, yaitu yang pertama faktor predisposisi (mencakup pengetahuan, sikap, tingkat pendidikan, usia, sosial ekonomi, pekerjaan dan sebagainya), kedua faktor pemungkin (mencakup sarana dan prasarana, dukungan sosial, suami dan keluarga), dan terakhir faktor pendorong atau penguat (sikap dan perilaku pada petugas kesehatan).

Sejalan dengan hasil penelitian (Tulas, 2017) tentang hubungan perawatan luka perineum dengan personal hygiene pada ibu post partum. Berdasarkan hasil penelitian pada 56 responden dengan perilaku personal hygiene baik sebanyak 47 responden $(94,0 \%)$, hal ini dikarenakan responden telah mengetahui tentang bagaimana cara perawatan luka perineum, serta ibu memiliki pendidikan yang tinggi, serta status gizinya yang baik sehingga ibu memiliki keyakinan dan nilai kesehatan dalam melakukan perawatan luka yang baik dan benar serta proses penyembuhan lukanya tentu lebih cepat.

Berdasarkan hasil kuesioner didapatkan ibu banyak menjawab salah pada pertanyaan nomor 3 mengenai cara membersihkan luka perineum, sebagian 
JURNAL OF MIDWIFERY CARE:

VOL. 01 NO. 02, JUNI 2021

DOI: $10.34305 / \mathrm{jmc} . \mathrm{V} 1 \mathrm{i} 02.307$
Ciptaan disebarluaskan di bawah

Lisensi Creative Commons Atribusi-

NonKomersial-BerbagiSerupa 4.0

Internasional. besar ibu menjawab dari arah belakang ke depan, sama halnya dengan hasil pengetahuan ibu dimana ibu sebagian besar menjawab bahwa cara mencuci perineum tersebut dari arah belakang ke depan. dengan demikian maka ibu perlu diberikan bimbingan dan konseling bagaimana cara membersihkan perineum yang baik. Di samping menurut (Saleha, 2009) proses pencucian harus dimulai dari depan ke belakang, dimana (Varney, 2008) juga mengungkapkan bahwa melepas pembalut dan mengeringkan kemaluan pun harus dimulai dari arah depan ke belakang agar tidak terjadi kontaminasi (masuknya) kuman dari anus ke perineum.

Analisis Bivariat

Berdasarkan tabel 2 menunjukkan hasil penelitian dari 13 responden yang memiliki pengetahuan baik seluruhnya memiliki perilaku optimal sebanyak 13 responden $(100 \%)$, dari 11 responden yang memiliki pengetahuan cukup sebagian besar memiliki perilaku optimal sebanyak 8 responden $(72,7 \%)$ dan dari 6 responden yang memiliki pengetahuan kurang seluruhnya memiliki perilaku tidak optimal yaitu sebanyak 6 responden (100\%). Hasil uji statistik dengan menggunakan Spearman's rank diketahui didapatkan nilai $\rho=0,001$ jadi nilai $\rho$ kurang dari $<0,05$ dengan demikian ada hubungan pengetahuan dengan perilaku ibu nifas dalam perawatan luka perineum dan nilai $\mathrm{r}=$ 0,774 artinya memiliki kekuatan yang kuat.

Pada ibu yang memiliki pengetahuan baik berarti ibu sudah berada pada tahap evaluasi. Hal ini dikarenakan perilaku ibu dalam perawatan luka perineum sudah optimal. Pengetahuan tidak akan lepas dari tahu atau mengingat tentang apa yang telah diberikan, memahami yang telah disampaikan, mempraktekkan atau menggunakan materi yang telah dipahami, mampu menjabarkan hubungan tentang apa yang telah dipahami sehingga mampu menyusun suatu karya yang mudah dipahami dan dapat menilai suatu materi atau obyek. Hal ini sesuai dengan pendapat (Riyanto, 2013) bahwa tahapan pengetahuan ada enam tahap yaitu mengetahui, memahami, mengaplikasikan (mencoba menerapkan), menganalisis, mensintesis (menghubungkan bagian-bagian di dalam suatu bentuk yang baru), lalu mengevaluasi (menilai). Begitu pula dengan perilaku dimana ibu menyadari dalam arti mengetahui bagaimana perawatan luka perineum yang baik, kemudian ibu tertarik untuk mencoba, selanjutnya menimbangnimbang apakah tindakannya baik atau benar, setelah dicoba ternyata membawa 
JURNAL OF MIDWIFERY CARE:

VOL. 01 NO. 02, JUNI 2021

DOI: $10.34305 / \mathrm{jmc} . \mathrm{V} 1 \mathrm{i} 02.307$
Ciptaan disebarluaskan di bawah

Lisensi Creative Commons Atribusi-

NonKomersial-BerbagiSerupa 4.0

Internasional. hasil yang positif, maka ibu melakukan perawatan yang optimal sesuai dengan pengetahuan yang ibu dapat, kesadaran dan sikap yang positif tanpa ada paksaan dari luar. Pada ibu nifas yang memiliki pengetahuan kurang berarti pengetahuan ibu baru pada tahap mengetahui, begitu juga pada ibu yang memiliki pengetahuan cukup sebagian besar pengetahuan ibu baru pada tahap memahami belum pada tahap evaluasi, dan perilaku ibu mencapai pada tahap mencoba tidak sampai melakukan secara optimal disebabkan karena pengetahuan ibu yang cukup dan kurang. Begitu juga mengenai perilaku sesuai dengan pendapat (Notoatmodjo, 2010) mengungkapkan bahwa sebelum orang mengadopsi perilaku baru atau berperilaku baru, yaitu dengan cara sadar, tertarik, menilai, mencoba dan melakukannya atau berperilaku baru sesuai dengan pengetahuan, kesadaran dan sikap terhadap stimulus.

Sejalan dengan hasil penelitian (Raudhatul J., 2013), dalam penelitiannya mengenai hubungan pengetahuan ibu nifas dengan perawatan luka ruptur perineum didapatkan ada hubungan antara pengetahuan ibu nifas dengan perawatan luka ruptur perineum dengan nilai $\rho=0,045$. Begitu juga dengan hasil penelitian (I'anah, 2013) dalam penelitiannya mengenai hubungan antara pengetahuan ibu nifas tentang personal hygiene pada luka perineum dengan penyembuhan luka fase proliferasi didapatkan bahwa ada hubungan yang signifikan antara pengetahuan ibu nifas tentang personal hygiene pada luka perineum dengan penyembuhan luka fase proliferasi dengan nilai $\rho=0,006$.

Berdasarkan hasil yang didapat peneliti berasumsi bahwa ibu nifas yang memiliki pengetahuan baik maka perilaku dalam perawatan luka perineum pun optimal, begitu juga sebaliknya pada ibu yang memiliki pengetahuan kurang maka perilaku dalam perawatan luka perineumnya pun tidak optimal. Akan tetapi pada ibu yang memiliki pengetahuan cukup sebagian besar perilaku ibu dalam perawatan luka perineumnya optimal. Dengan demikian semakin baik pengetahuan ibu maka semakin optimal juga dalam perawatan luka perineumnya.

\section{Kesimpulan}

Berdasarkan hasil penelitian tentang hubungan pengetahuan dengan perilaku ibu nifas dalam perawatan luka perineum di Wilayah Kerja UPTD Puskesmas Sukamulya dan Kadugede maka penulis membuat kesimpulan sebagai berikut: 
JURNAL OF MIDWIFERY CARE:

VOL. 01 NO. 02, JUNI 2021

DOI: $\underline{10.34305 / j m c . v 1 i 02.307}$
Ciptaan disebarluaskan di bawah

Lisensi Creative Commons Atribusi-

NonKomersial-BerbagiSerupa 4.0

Internasional.
1. Gambaran pengetahuan ibu nifas tentang perawatan luka perineum di Wilayah Kerja UPTD Puskesmas Sukamulya dan Kadugede hampir setengahnya berpengetahuan baik sebanyak 43,3\% .

2. Gambaran perilaku ibu nifas dalam perawatan luka perineum di Wilayah Kerja UPTD Puskesmas Sukamulya dan Kadugede sebagian besar berperilaku optimal sebanyak $70 \%$.

3. Terdapat hubungan antara pengetahuan dengan perilaku ibu nifas dalam perawatan luka perineum di Wilayah Kerja UPTD Puskesmas Sukamulya dan Kadugede dengan nilai $\rho=0,001$.

\section{Daftar Pustaka}

Bahiyatun. (2009). Buku Ajar Asuhan Kebidanan Nifas Normal. Jakarta: EGC.

Chasanah, S. N, Susanto. D, Arisanti, N. L. (2015). Gambaran Prilaku Ibu Nifas dalam Perawatan Luka Perineum di Kelurahan Kabupaten Brebes.Http://Ejournal.Poltektegal.Ac. Id/Index.Php/Siklus/Article/View/244.

Herawati, P. (2010). Hubungan Perawatan Perineum Dengan Kesembuhan Luka Perineum Pada Ibu Nifas Hari Keenam Di Bidan Praktik Swasta (Bps) Ny. Sri Suhersi Mojokerto Kedawung Sragen. Universitas Sebelas Maret Surakarta.Https://Eprints.Uns.Ac.Id/ 10328/1/15406210820100623 1. Pdf.
I'anah, S. (2013). Hubungan antara pengetahuan ibu nifas tentang personal hygiene pada luka perineum dengan penyembuhan luka fase proliferasi. Akademi Kebidanan Harapan Ibu Pekalongan.

Http://Download.Portalgaruda.Org/Ar ticle.Php?Article.

Kemenkes RI. (2016). Profil Kesehatan Indonesia Tahun 2015. In Jakarta: KemekesRI.http://www.depkes.go.id/re sources/download/pusdatin/profilkese hatan- indonesial profil- kesehatan Indonesia-2015.pdf.

Khusniyati, E., Dewi, C.P. L., H. V. (2016). Hubungan Perawatan Luka Perineum Dengan Lama Penyembuhan Luka Perineum Pada Ibu Nifas Di BPM Ny. Titi Ekawati, Str. Keb Desa Tampungrejo Kecamatan Puri Mojokerto. STIKes Bina Sehat PPNI Mojokerto., Vol.14(No. 2).

Notoatmodjo, S. (2010). Ilmu Perilaku Kesehatan. Jakarta: Jakarta: Rineka Cipta.

Raudhatul J. (2013). Hubungan Pengetahuan Ibu Nifas dan Pantangan Makanan dengan Perawatan Luka Ruptur Perineum di Rumah Sakit Ibu dan Anak.

Http://Simtakp.Uui.Ac.Id/Dockti/Raud hatul_jannah-Kumpulan_kti_atun_pdf.

Riyanto, B. \&. (2013). Kapita Selekta Kuisioner Pengetahuan Dan Sikap Dalam Penelitian Kesehatan. Jakarta: Salemba Medika.

Rukiah, A. (2010). Asuhan Kebidanan II Persalinan. Jakarta: Trans Info Media.

Saleha, S. (2009). Asuhan Kebidanan Pada 
JURNAL OF MIDWIFERY CARE:

VOL. 01 NO. 02, JUNI 2021

DOI: $10.34305 / \mathrm{jmc} . \mathrm{v} 1 \mathrm{i} 02.307$
Ciptaan disebarluaskan di bawah Lisensi Creative Commons AtribusiNonKomersial-BerbagiSerupa 4.0

Internasional.

Masa Nifas. Jakarta: Salemba Medika.

Tulas. (2017). Hubungan Perawatan Luka Perineum Dengan Perilaku Personal Hygiene Ibu Post Partum Di Rumah Sakit Pancaran Kasih GMIM Manado. Universitas Sam Ratulangi Manado. EJournal Keperawatan, 5(No. 1).

Varney H. (2008). Buku Ajar Asuhan Kebidanan Edisi 4 Volume 2. Jakarta: EGC. 